Published in final edited form as:

Cell Tissue Res. 2017 October ; 370(1): 179-193. doi:10.1007/s00441-017-2651-7.

\title{
Combined effects of oscillating hydrostatic pressure, perfusion and encapsulation in a novel bioreactor for enhancing extracellular matrix synthesis by bovine chondrocytes
}

\author{
Arshan Nazempour ${ }^{1}$, Chrystal R. Quisenberry ${ }^{1}$, Nehal I. Abu-Lail ${ }^{1}$, and Bernard J. Van Wie ${ }^{1}$ \\ ${ }^{1}$ Gene and Linda Voiland School of Chemical Engineering and Bioengineering, Washington State \\ University, Pullman, WA 99164-6515, USA
}

\begin{abstract}
The influence of combined shear stress and oscillating hydrostatic pressure (OHP), two forms of physical forces experienced by articular cartilage (AC) in vivo, on chondrogenesis, is investigated in a unique bioreactor system. Our system introduces a single reaction chamber design that does not require transfer of constructs after seeding to a second chamber for applying the mechanical forces, and, as such, biochemical and mechanical stimuli can be applied in combination. The biochemical and mechanical properties of bovine articular chondrocytes encapsulated in agarose scaffolds cultured in our bioreactors for 21 days are compared to cells statically cultured in agarose scaffolds in addition to static micromass and pellet cultures. Our findings indicate that glycosaminoglycan and collagen secretions were enhanced by at least 1.6-fold with scaffold encapsulation, 5.9-fold when adding 0.02 Pa of shear stress and 7.6-fold with simultaneous addition of $4 \mathrm{MPa}$ of OHP when compared to micromass samples. Furthermore, shear stress and OHP have chondroprotective effects as evidenced by lower $m R N A$ expression of $\beta 1$ integrin and collagen $\mathrm{X}$ to non-detectable levels and an absence of collagen I upregulation as observed in micromass controls. These collective results are further supported by better mechanical properties as indicated by 1.6-19.8-fold increases in elastic moduli measured by atomic force microscopy.
\end{abstract}

\section{Keywords}

Articular cartilage tissue engineering; Agarose; Oscillating hydrostatic pressure; Shear stress; Young's modulus

\section{Introduction}

Articular cartilage (AC) lacks blood vessels, nerves and lymphatics and therefore upon injury has limited repair ability (Cui et al. 2012). AC damage often leads to osteoarthritis (OA), which is among the ten most costly diseases worldwide (Hasty et al. 2014), with

Correspondence to: Bernard J. Van Wie.

Bernard J. Van Wie (D) http://orcid.org/0000-0001-7382-9715

Arshan Nazempour and Chrystal Quisenberry contributed equally to this manuscript.

Compliance with ethical standards

Conflict of Interest The authors declare that they have no conflict of interest. 
orthopedic repairs costing $\$ 28$ billion per year in the US alone (Chao et al. 2007). Current treatments such as abrasion arthroplasty, microfracture, and autologous osteochondral grafting lead to repaired tissues that poorly replicate the biochemical and biomechanical properties of normal AC (Olee et al. 2013; Wescoe et al. 2008).

AC tissue engineering (ACTE) represents a promising approach to overcome the limitations of current treatments and consists of four main components: (1) an abundant source of cells that can proliferate and synthesize proteoglycans, collagen II (Col II) and aggrecan (ACAN) (Cooke et al. 2011); (2) a biocompatible, 3-D scaffold allowing spatially uniform cell attachment for maintaining cell phenotype (Augst et al. 2008); (3) chondrogenic factors to direct development of cells toward a chondrogenic lineage; and (4) bioreactors that more closely mimic the in vivo environment of tissue in vitro and support tissue reconstruction by regulating the microenvironment through precise control of medium, mass transfer to and from the cells, shear forces and hydrodynamic pressures, as well as proper regulation of environmental conditions in the bioreactors such as $\mathrm{pH}$, temperature and $\mathrm{O}_{2}$ tension (Mauck et al. 2000).

Knee-joint AC experiences 3.9 and 8 times the body weight for level and downhill walking (Kuster et al. 1997), respectively. Therefore, one can presume that the desired physiological function in engineered tissue cannot be achieved without mechanical stimulation. In the majority of studies, individual roles of mechanical stimuli such as uniaxial compression (Angele et al. 2004; Campbell et al. 2006), perfusion (Khan et al. 2009; Sittinger et al. 1994) and hydrostatic pressure (Miyanishi et al. 2006; Wagner et al. 2008) have been shown to enhance extracellular matrix (ECM) synthesis by chondrocytes. A few studies have examined the combined effects of mechanical stimuli, e.g., compression and shear (Kupcsik et al. 2010; Li et al. 2010) and perfusion and loading (Grogan et al. 2012; Tran et al. 2011). However, in most cases, if not all, cells are grown in a Petri dish and then transferred to the bioreactor where mechanical forces are applied, increasing the risk of bacterial contamination. Another disadvantage with common protocols for studying combined effects of mechanical forces is that the individual role of each stimulus cannot be investigated. This study focuses on a novel bioreactor that provides a seamless procedure throughout the culture period for studying the effects of oscillating hydrostatic pressure (OHP), perfusioninduced surface shear stress and provision of chondrogenic medium (CM) on chondrogenesis.

In this study, our aim is to determine the effects of OHP, shear stress and CM supplementation, separately and in combination, on chondrogenesis of bovine articular chondrocytes (bAChs) encapsulated in a $2 \%$ agarose hydrogel. We chose bAChs as they have been widely used in ACTE (Gharravi et al. 2016; Kawanishi et al. 2007) and represent an inexpensive and accessible cell source compared to human-derived chondrocytes, which are limited in availability as they are harvested from patient joint replacements or from cadavers. Moreover, agarose was used as the scaffold of choice because it supports growth and chondrogenic differentiation and reverses dedifferentiation phenomena where dedifferentiated chondrocytes (Chs) re-express the differentiated phenotype after encapsulation (Benya and Shaffer 1982). Furthermore, when encapsulated in agarose, bAChs maintain their phenotype and ability to synthesize Col II and ACAN (Buschmann et 
al. 1992; Kessler and Grande 2008). We hypothesize that our perfusion bioreactor, because it is capable of applying OHP, will enhance chondrogenic differentiation and the functional properties of the resulting tissue by providing mechanical and biochemical stimuli that mimic in vivo environments. By contrast, in the past, our centrifugal bioreactor operated in two different modes where cells were either inoculated into the reactors while the reactors were spinning (Detzel and Van Wie 2011) or injected into the reactors and then spun in a scaffold-free mode (Nazempour et al. 2016).

Once constructs have been engineered, measuring the biochemical and mechanical properties of engineered cartilage is critical, especially if they are to be used in repairing damaged sites in the joint. Therefore, to characterize samples, we investigated genetic expression using Taqman for $m R N A$ analysis of $\beta 1$ integrin, Col $\mathrm{X}$ and $\mathrm{Col} \mathrm{I}$, biochemical composition of glycosaminoglycan (GAG), collagen ( $\mathrm{Col})$ and $D N A$ content using dimethylmethylene blue, chloramine-T hydroxyproline, and Quant-iT PicoGreen analyses, respectively and mechanical properties of the tissues using atomic force microscopy (AFM) nanoindentation. AFM has proven to be an effective tool for determining the mechanical properties of biological tissues since it allows measurements under near-native conditions such as in liquid environments and because of the correlation found between ECM deposition and construct mechanical properties reported previously (Chiang et al. 2011; Loparic et al. 2010; Zhu et al. 2011).

\section{Materials and Methods}

Cell culture supplies were purchased from Invitrogen-Gibco ${ }^{\circledR}$, Grand Island, NY, USA, unless otherwise specified.

\section{Isolation and expansion of bAChs}

Chondrocytes were harvested from skeletally mature bovine animals from full thickness cartilage tissues from metacarpal pastern joints (front knees) donated by local meat packinghouses (e.g., Potlach Pack, Potlach, ID, USA). Chondrocytes from these joints have been widely used in previous studies (Badger et al. 1998; Fukuda et al. 1996; Lo et al. 2009; McGann et al. 1988; Wang and Kandel 2004) as they are derived from a significant weightbearing joint. We began with joint disarticulation under aseptic conditions and shaving off sections of cartilage. To isolate $\mathrm{Chs}$ from the tissue matrix, tissues were cut into small pieces and digested for $16 \mathrm{~h}$ at $37^{\circ} \mathrm{C}$ in high-glucose Dulbeco's Modified Eagle's Medium (HGDMEM/ F12) containing 0.2\% collagenase type II (Worthington Biochemical, Lakewood, NJ, USA), $5 \%$ fetal bovine serum (FBS), $5 \mu \mathrm{g} / \mathrm{mL}$ gentamicin $100 \mathrm{U} / \mathrm{mL}$ of penicillin and $100 \mu \mathrm{g} / \mathrm{mL}$ of streptomycin. The cell suspension was then filtered through a 70- $\mu \mathrm{m}$ cell strainer (Falcon, Franklin Lakes, NJ, USA) and washed three times with phosphate-buffered saline (PBS) containing $5 \mu \mathrm{g} / \mathrm{mL}$ gentamicin, $100 \mathrm{U} / \mathrm{ml}$ penicillin and $100 \mathrm{mg} / \mathrm{ml}$ streptomycin. After the third wash, bAChs were frozen in a 7:2:1 ratio of HGDMEM/F12:FBS:dimethyl sulfoxide at $-80^{\circ} \mathrm{C}$ for storage until cells from at least three donors were pooled to reduce subject-to-subject variation and to obtain sufficient numbers of cells for our experiments. 


\section{bACh-agarose hydrogel encapsulation}

Type VII agarose (Sigma-Aldrich, St. Louis, MO, USA) with a final concentration of 0.04 $\mathrm{mg} / \mathrm{ml}$ was dissolved in PBS at $120^{\circ} \mathrm{C}$. Once dissolved, the temperature was lowered to $60{ }^{\circ} \mathrm{C}$, as higher temperatures will affect cell viability. To obtain $2 \%$ agarose hydrogels, equal 5 -ml volumes of $4 \%$ agarose and a $40 \times 10^{6}$ cells $/ \mathrm{ml}$ both in PBS were thoroughly mixed. The bACh-seeded agarose was then aliquoted into $60-\mathrm{mm}$ Petri dishes and allowed to solidify at room temperature. bACh-agarose constructs $5 \mathrm{~mm}$ in height were obtained using a 4-mm biopsy punch. Constructs, measured with the use of a sterilized micrometer in $70 \%$ ethanol, with a sample height variance greater than $\pm 2 \%$ were discarded. On average, each single construct had 250,000 cells as calculated below:

$$
\text { Volume }_{\text {construct }}=\pi R_{\text {cylinder }}^{2} \times \text { Height }_{\text {cylinder }}=3.14 \times(0.002)^{2} \times(0.005)=6.28 \times 10^{-8} \mathrm{~m}^{3}
$$

$$
\begin{aligned}
& \text { \# cells per cylindrical construct }=\text { Volume }_{\text {construct }} \times \text { cell density } \\
& =6.28 \times 10^{-8} \mathrm{~m}^{3} \times \frac{10^{6} \mathrm{ml}}{1 \mathrm{~m}^{3}} \times \frac{40 \times 10^{6} \mathrm{Cells}}{10 \mathrm{ml}} \\
& \cong 250,000 \text { cells per contruct }
\end{aligned}
$$

\section{Chondrogenic differentiation}

Micromass culture-Cells were thawed and re-suspended in expansion medium (EM) containing HG-DMEM/F12 supplemented with $10 \%$ FBS, $100 \mathrm{U} / \mathrm{ml}$ penicillin, $100 \mu \mathrm{g} / \mathrm{ml}$ streptomycin (Sigma-Aldrich) and $5 \mu \mathrm{g} / \mathrm{ml}$ gentamicin at $1.6 \times 10^{7} \mathrm{cells} / \mathrm{ml}$. Micromass cultures were established by placing 10- $\mu$ droplets of cell suspensions in the center of each well in a 24-well plastic plate and cultured under standard conditions for $2 \mathrm{~h}$. After cell adherence, $600 \mu \mathrm{l}$ of fresh EM was added. After a day, $250 \mu \mathrm{EM}$ was removed and replaced with either a base medium (BM) consisting of HG-DMEM/F12 supplemented with $1 \mathrm{mM}$ sodium pyruvate, $2 \mathrm{mM}$ L-glutamine, $5 \mu \mathrm{g} / \mathrm{ml}$ Gentamicin, $1 \%$ Insulin-TransferrinSelenium, $50 \mu \mathrm{M}$ L-proline (Alfa Aesar, Ward Hill, MA, USA) and 1\% penicillinstreptomycin (Sigma-Aldrich), or in a chondrogenic medium (CM) consisting of BM with $100 \mathrm{nM}$ dexamethasone, $50 \mu \mathrm{g} / \mathrm{ml}$ L-ascorbic acid (both Sigma-Aldrich) and $10 \mathrm{ng} / \mathrm{ml} \mathrm{TGF-}$ $\beta 3$ (PeproTech, Ward Hill, NJ, USA) (Fig. 1a). Micromass samples are referred to as M- if supplied with BM and as M+ if supplied with $\mathrm{CM}$.

Pellet culture-Aliquots of $5 \times 10^{5}$ cells, suspended in $600 \mu \mathrm{EM}$, were centrifuged at $600 \mathrm{~g}$ for $10 \mathrm{~min}$ in $15-\mathrm{ml}$ polypropylene conical tubes. Pelleted cells were incubated at standard conditions with loose caps to permit gas exchange. After a day, cells settled and formed spherical aggregates. Similar to the micromass, half the medium was replaced by either BM or CM. Pellet samples supplied by either BM or CM are referred to as Pel - or Pel+, respectively (Fig. 1b).

Static-Scaffold culture-bACh-agarose hydrogels were cultured in Petri dishes and supplied with EM. After a day, half the medium was replaced with BM or CM. Because no 
mechanical stimulus was present, these samples were considered as static-scaffold cultures and referred to as $\mathrm{S}-$ if supplied with BM and as $\mathrm{S}+$ if supplied with $\mathrm{CM}$ (Fig. 1c).

Scaffold bioreactor culture-For the bioreactor study, after sterilizing the system by pumping $70 \%$ ethanol for $24 \mathrm{~h}, 15 \mathrm{bACh}$-agarose hydrogels were placed into each of eight 3D funnel-shaped bioreactors. After a day, half of the EM in all bioreactors was replaced with either BM or CM. To distinguish the effects of surface shear stress and OHP from shear stress alone, four bioreactors were subjected to combined perfusion and OHP, while in the other four we applied only surface shear stress resulting from medium pumped continuously from the reservoirs at a $0.5-\mathrm{ml} / \mathrm{min}$ flow rate. This corresponds to perfusion at a velocity of $0.001 \mathrm{~m} / \mathrm{s}$ at the reactor inlet and results in an average $0.02 \mathrm{~Pa}$ shear stress at the scaffold surface as determined through a COMSOL Multiphysics ${ }^{\circledR}$ model of the system (simulation results not shown). Surface shear stress in our study is in the range of perfusion-induced shear stress of $5 \times 10^{-5}-1.6 \mathrm{~Pa}$, shown to increase cell proliferation and enhance GAG synthesis (Porter et al. 2005; Smith et al. 1995). Scaffold constructs from bioreactors with OHP are labeled as SOHP and scaffolds from bioreactors with perfusion but no OHP are referred to as SP (Fig. 1d).

Schematics of the bioreactor itself and the overall system are shown in Fig. 2a, b, and a photo of the bioreactor in Fig. 2a. The pressurization procedure has been presented elsewhere (Nazempour et al. 2016). Briefly, to expose cells to high pressure, we first stopped the medium flow and closed corresponding shut off valves (IDEX Health and Science, Oak Harbor, WA, USA). Next, compressed air moves the rod of a pancake tie rod air cylinder (McMaster-CARR, Los Angeles, CA, USA), which, in sequence, pressurizes hydraulic oil within a hydraulic cylinder that pushes on aluminum pistons connected by screws to polycarbonate pistons at the top of each bioreactor (Fig. 2a) which finally pressurizes the liquid medium content. For OHP, a directional control three-way solenoid valve (Parker, Cleveland, OH, USA) in connection with an 8-channel USB relay card was used (Vellman, Fort Worth, TX, USA). Pressure transducers (DJ Instrument, Billerica, MA, USA) and an NI USB-6008 data acquisition devise (National Instrument, Austin, TX, USA) were used to read pressures. bACh-agarose hydrogels were exposed to OHP at $1 / 2 \mathrm{~Hz}$ at $4 \mathrm{MPa}$ for $4 \mathrm{~h}$ per day and 5 days a week for 3 weeks. The magnitude of $4 \mathrm{MPa}$ and frequency of $1 / 2 \mathrm{~Hz}$ were chosen as increases in ECM production were observed in previous studies when cells were subjected to similar conditions (Angele et al. 2003; Elder and Athanasiou 2008; Hall et al. 1991). After pressurization, we opened the shutoff valves and restarted continuous medium flow. Visual inspection of bACh-agarose constructs subjected to this loading regimen revealed that they withstood this repeated mechanical stimulus.

A mixture of 5\% $\mathrm{CO}_{2}$ and air was continuously pumped using a 20-60-gallon (c.230-L) Aquarium Air Pump from AQUA CULTURE, to all bioreactors for the culture duration. Reactor samples were found to be free of contamination as tested on tryptic soy agar plates. For all micromass, pellet and bioreactor cultures, half the medium was exchanged three times a week. 


\section{Quantitative biochemistry}

Samples for biochemical analyses were digested for $16 \mathrm{~h}$ in $125 \mu \mathrm{g} / \mathrm{ml}$ papain (SigmaAldrich) in $100 \mathrm{mM}$ sodium phosphate buffer (pH 6.5) containing $10 \mathrm{mM} \mathrm{L}$-cysteine and 10 mM EDTA at $65^{\circ} \mathrm{C}$. Total sulfated GAG was then quantified using a 1,9-dimethylmethylene blue assay (Farndale et al. 1986). Samples were further assayed for total collagen content by a chloramine-T hydroxyproline assay (Woessner 1961). Finally, total $D N A$ content was measured using a Quant-iT PicoGreen $d s D N A$ Assay Kit. Total collagen and GAG contents were normalized to the amount of $D N A$ in samples so that protein production could be compared on a per cell basis. This approach accounts for differences in cell density between samples, i.e., micromass, pellets, and scaffolds, since each cell has a similar amount of DNA.

\section{$R N A$ isolation and analysis}

Quantitative real-time polymerase chain reaction (qRT-PCR) was used to quantify gene expression (Quisenberry et al. 2016). Briefly, total $R N A$ was isolated with TRIzol and chloroform was used for phase separation. Total $m R N A$ (up to $2.5 \mu \mathrm{g}$ ) was reversetranscribed into $c D N A$ using the SuperScript ${ }^{\circledR}$ VILO ${ }^{\text {TM }}$ Master Mix. $c D N A$ was amplified with the TaqMan ${ }^{\circledR}$ Gene Expression Master Mix (Applied Biosystems by Life Technologies, Grand Island, NY, USA) on an ABI 7900HT Sequence Detection System (Applied Biosystems) and probes specific for GAPDH (housekeeping gene), Col X, Col I, and integrin $\beta 1$ were used. The relative gene expression was calculated using the $\Delta \Delta \mathrm{C}_{\mathrm{T}}$ method and fold differences were determined using the expression $2-\Delta \Delta C T$ (Schmittgen and Livak 2008), where bACh values prior to differentiation assays at day 0 were considered as the reference values.

\section{Cantilever preparation}

Custom colloidal silicon nitride AFM probes were constructed from tipless AFM cantilevers (spring constant $0.08 \mathrm{~N} / \mathrm{m}$; NanoAndMore USA, Soquel, CA, USA). Borosilicate microspheres (5.20 $\mu \mathrm{m}$ in diameter; Bangs Laboratories, Fishers, IN, USA) were attached near the free end of the AFM cantilever with Norland optical adhesive \#81 (Norland Products, Cranbury, NJ, USA). The spherical probe serves as a model of a single asperity and as such the contact area during sliding is known (Coles et al. 2008). To ensure uniformity, cantilevers were coated with $40 \mathrm{~nm}$ of gold over a 5-nm adhesion layer of chromium in a thermal evaporator. The mounted probe was submerged in PBS for at least 20 min prior to imaging to allow for thermal equilibration at room temperature.

\section{AFM measurements}

For AFM elastic moduli measurements, cylindrical agarose scaffolds ( $10 \mathrm{~mm}$ in height) were cut in half and glued with Pelco Pro CA44 Instant Tissue Adhesive (Ted Pella, Redding, CA, USA) to AFM metal specimen disks (Ted Pella) and placed on an AFM sample stage for subsequent indentation studies. All AFM force measurements were performed with a PicoForce scanning probe microscope with a Nanoscope IIIa controller and extender module (Bruker AXS, Santa Barbara, CA, USA) using the silicon nitride cantilevers described earlier. 
AFM indentation tests were performed using the point and shoot function of Nanoscope $v$. 6.13 software following a $16 \times 16$ grid of equally spaced indentation points on a $10 \mu \mathrm{m} \times 10$ $\mu \mathrm{m}$ area of each AC tissue sample. The trigger threshold was set to $5 \mathrm{nN}$ with a ramp size of $2 \mu \mathrm{m}$ and tip velocity of $4.1 \mu \mathrm{m} / \mathrm{s}$. Given that the ratio of the scanned area to that of the AFM tip is 20:5, selecting 16 points on each scan line ensured that the points were spaced apart to collect force curves from all locations in the scanned area. Each sample was scanned in PBS in at least 3 areas per treatment group. At each pixel, both approach and retraction curves were collected but only approach curves are analyzed in this work.

\section{Determination of Young's moduli: Hertz model}

AFM approach position-deflection data files were converted to force-indentation files as described previously (Abu-Lail and Camesano 2006). To quantify the Young's modulus, approach curves were fit to the Hertz contact model that assumes an infinitely hard sphere indenting a flat, deformable elastic substrate as described in Eq. 1:

$$
F=\frac{4}{3} \times \frac{E_{\gamma} R^{1} / 2 \delta^{3} / 2}{1-v^{2}}
$$

where $F$ is the applied force, $E_{\gamma}$ is the Young's modulus, $R$ is the relative radius, $v$ is Poisson's ratio, and $\delta$ is the indentation depth. Once all force-indentation profiles were collected in a force-volume image, data were analyzed for their Young's moduli, and a histogram that describes the heterogeneity in the data was generated. Although cartilage is innately heterogeneous, elastic moduli in the different areas scanned within treatment groups were all of similar distributions, e.g., bioreactor SOHP- constructs have statistically similar mean elastic moduli via one-way ANOVA $(P=0.057)$. In Table 1 we present a typical example for three separate areas in the SOHP- treatment group, with 80-101 scans per area; and show the mean, median, standard deviation, and standard error of the mean are in good agreement.

Although the Hertz model has limitations, we believe it is appropriate for our purposes for the following three reasons: first, the sample surface is continuous and non-conforming; second, the radii of the contacting bodies are large compared to the contact area so that surfaces can be approximated as an elastic half-space (Barquins and Maugis 1982); and third, substrate effects can be ignored because the indentation depth $(\sim 900 \mathrm{~nm})$ is much smaller than sample thickness $(300 \mu \mathrm{m})$ (Long et al. 2011; Santos et al. 2012). Only normal pressures are applied during indentation because there is a lubricated layer between the machine parts and the sample, so friction can be neglected and the indentation is on the nanometer scale, and thus strains will be small. This means that stresses and strains produced are not dependent on the sample or probe geometry (Fischer-Cripps 1999). Although cartilage is a viscoelastic material, we only used the Hertz model to fit the elastic portion of the approach curve. 


\section{Statistical analysis}

Statistical analysis was performed using Prism 7 (GraphPad Software, La Jolla, CA, USA) software. One-way analysis of variance (ANOVA) was used with the Tukey test to determine significant differences between treatment groups $(P<0.05)$. In the presented figures, significant differences are indicated when a letter is not shared by the resulting data bar.

\section{Results and Discussion}

\section{Quantitative biochemistry}

When examining biochemical chondrogenic indices, progressive improvements were observed in GAG/DNA content when subjecting cell-laden agarose scaffolds to perfusion and then perfusion plus OHP as shown in Fig. 3a. Because no significant differences in GAG/DNA content were observed between free-swelling scaffold-free samples, i.e., micromass (M) and pellet (Pel), micromass samples were considered as controls. Encapsulation in agarose significantly increased GAG/DNA content of $\mathrm{S}-$ and $\mathrm{S}+$ cultures by 22- and 11.2-fold over their respective $\mathrm{M}-$ and $\mathrm{M}+$ controls. This is consistent with a study by Buschmann et al. (1992) where agarose-encapsulated bAChs resulted in a GAGrich matrix around individual cells according to histological analyses. As such, the agarose may be acting to retain the large GAG molecules (Sittinger et al. 1994). When perfusion is applied in concert with scaffolds (SP) significant increases of 30- and 21-fold higher GAG/DNA content are observed in SP- and SP+ controls, which are 1.4- and 1.8-fold higher than the stagnant non-perfused $\mathrm{S}-$ and $\mathrm{S}+$ counterparts. This is consistent with studies by Davisson et al. (2002) in which samples subjected to perfusion-induced shear stress secreted 40\% more GAG than static counterparts and by Santoro et al. (2010) where perfusion showed stronger and more homogenous Safranin-O staining compared to static controls. Adding OHP further enhances chondrogenic indicators where GAG/ DNA for SOHP- and SOHP+ samples are 44- and 32-fold higher than respective controls, and, significantly, 1.9- and 2.7-fold, higher than the SP- and SP+ counterparts. This finding strongly supports the premise that scaffold encapsulation, perfusion and OHP work together and are important for optimizing chondrogenesis. These findings are supported by the literature where Lee and Bader (1997) showed that GAG content increased by $40 \%$ when a static $15 \%$ compressive strain at $1 \mathrm{~Hz}$ frequency for 48 hours was added to chondrocyteseeded agarose. Dynamic compression of bACh-seeded agarose was shown by Chai et al. (2010) to increase GAG accumulation by $14 \%$. Seidel et al. (2004) utilized a bioreactor with perfusion and dynamic compression, which led to increased GAG deposition as evidenced by strong Safranin-O staining. Individual effects of perfusion and the additive effects of loading on GAG secretion were not distinguished in any of these prior studies.

Similarly, Fig. 3b indicates significant progressive enhancements in $\mathrm{Col} / D N A$ content with 2.3- and 1.6-fold increases with encapsulation, 5.9- and 8.4-fold when adding perfusion and 7.6- and 8.7-fold increases with simultaneous addition of OHP when compared to respective $\mathrm{M}$ - and M+ samples. This is consistent with studies by Xu et al. (2006) who showed a significant increase in Col deposition in alginate encapsulated bAChs with perfusioninduced shear stress as evidenced by heavier Alcian blue staining and by Gemmiti and Guldberg (2006) who showed a significant 1.2-fold increase in Col content for bAChs with 
perfusion. Applying OHP, without perfusion, at $10 \mathrm{MPa}$ and $1 \mathrm{~Hz}$ for $4 \mathrm{~h}$ a day, 5 days per week was shown by $\mathrm{Hu}$ and Athanasiou (2006) to result in a significant 1.2-fold increase in Col production by bACh-agarose constructs compared to static controls. More recently, Tran et al. (2011) utilized a commercial C9-x CartiGen bioreactor with simultaneous perfusion and cyclic unconfined compression to study chondrogenesis of porcine AChs and observed no significant difference in Col content for static, perfused or loaded groups. By contrast, our system shows striking improvements, double, triple and quintuple the Col of 2.5- and 5.3-fold with perfusion, then 3.3- and 5.5-fold with perfusion plus OHP when comparing to the $\mathrm{S}-$ and $\mathrm{S}+$ counterparts. Moreover, our bioreactor is unique in that cell-scaffold constructs can be maintained with or without perfusion or OHP in one seamless system without transfer requirements from Petri dishes to bioreactors for mechanical forces to be applied as is necessary in other systems (Bilgen et al. 2013; Kaupp et al. 2012).

When CM was used, surprising results were obtained. Micromass and pellet controls showed no significant differences in GAG or Col synthesis with or without CM. This may be attributable to the fact that both micromass and pellet cultures mimic the microenvironment of living tissues by providing a three-dimensional environment that allows cell-cell interactions (Zhang et al. 2010) that result in similar stimulation. Also, use of CM led to decreases or insignificant changes in chondrogenic indices for the scaffold with 1.76- and 2.46-fold decreases in respective GAG/DNA and $\mathrm{Col} / D N A$ levels, perfusion with a 1.35 -fold decrease and no significant change, and OHP with 1.32- and 1.46-fold respective decreases. This is in contrast to the 7-fold enhancement in GAG observed by Morales and Roberts (1988) for bACh samples supplied with CM. Our GAG results are more consistent with those of Shintani and Hunziker (2011) with bovine bone-marrow-derived mesenchymal stem cell (BMSC) micromass and Xu et al. (1996) with bACh pellets, where insignificantly higher GAG content and only slightly stronger staining for GAG were observed with CM.

\section{Gene analysis}

To further assess culture condition effects on ECM deposition, we analyzed $\beta 1$ integrin $m R N A$ expression reduction as indicative of a sufficiently robust matrix (Quisenberry et al. 2016) and Col I and Col $X$ as indicative of less chondrogenic conditions. Integrins are transmembrane receptors consisting of $\alpha$ and $\beta$ subunits that are involved in cell adhesion to ECM (Grashoff et al. 2003; Knudson and Loeser 2002) and are therefore expected participants in mechanotransduction (Knudson and Loeser 2002). $\beta 1$ integrin inhibition early in culture completely hinders matrix synthesis (Shakibaei 1998). $\beta 1$ integrins are upregulated during differentiation but are downregulated in mature cells (Luo et al. 2012). Col $\mathrm{X}$ is a hypertrophic marker expressed by terminally differentiating chondrocytes (Schmid and Linsenmayer 1985). Col I, the most abundant collagen in our bodies, is a fibrocartilage marker and is highly expressed by immature cartilage to later be replaced by Col II (Tallheden et al. 2004). In vitro, Col I is upregulated when chondrocytes are expanded in a monolayer and de-differentiate (Nazempour and Van Wie 2016). We hypothesize that $\beta 1$ integrin, $\mathrm{Col} \mathrm{X}$ and Col I will decrease in mature healthy cultures by day 21 .

Our postulate is supported by our findings. First, as shown in Fig. 4, M- and M+ samples at day 21 show the highest $\beta 1$ integrin expression with $M+$ significantly higher than other 
experimental groups. The conditions considered to be more chondrogenic including the pellets $\mathrm{P}-$ and $\mathrm{P}+$, scaffolds, $\mathrm{S}-$ and $\mathrm{S}+$ and the addition of perfusion with and without $\mathrm{CM}$, $\mathrm{SP}+$ and $\mathrm{SP}-$, show suppressed $\beta 1$ integrin levels. $\beta 1$ integrin becomes non-detectable (nd) at day 21 when adding CM to perfusion, as well as when adding OHP. This affirms our biochemical analysis of significant improvement in GAG and total Col syntheses as observed in SP and SOHP compared to M samples where a healthier ECM is expected to coincide with downregulation of $\beta 1$ integrins. This is further supported by our previous study on scaffold-free human adipose-derived stem cells (hADSCs) in which less robust ECM, as evidenced by 203- and 105-fold lower elastic moduli, corresponded to 2.4- and 3.8fold higher $\beta 1$ integrin $m R N A$ expression at day 21 for micromass and pellet cultures, respectively, compared to bioreactor cultures with OHP (Quisenberry et al. 2016).

Further confirmation that we are enhancing chondrogenic conditions is offered by our ColX and Col I indices. As shown in Fig. 5a, all culture conditions but S- reveal suppressed expression of Col X compared to unstimulated bAChs. Moreover, Col X did not vary significantly among free-swelling scaffold-free samples and was suppressed to nondetectable levels in all bioreactor samples. These results are consistent with those by Tran et al. (2011) and Grogan et al. (2012) who also did not detect Col X when porcine and human chondrocytes were subjected to either perfusion or cyclic unconfined compression, respectively. Type X collagen is expressed by hypertrophic chondrocytes (Schmid and Linsenmayer 1985) and it reduces ECM ability to withstand the pressure and shear force that the joint is subjected to by facilitating ECM calcification and mineralization (Bigdeli et al. 2009). These results indicate the importance of mechanical stimuli, in this case with perfusion and OHP, in suppressing expression of the hypertrophic Col X marker.

Type I collagen is the primary collagen in the skin, bone, adipose tissue and fibrocartilage but not articular cartilage. Enhanced expression of Col I is also considered phenotypical of OA chondrocytes (Sandell and Aigner 2001). Regarding Col I, all our culture conditions upregulated Col I expression as shown in Fig. 5b. However, as expected, higher levels of Col I were detected in micromass samples, with $\mathrm{M}+$ significantly higher than all other groups but S+. Consistent with previous studies (Hering et al. 1994; Tekari et al. 2015), we also note that addition of CM caused significant 4.4- and 23- fold increases in Col I expression in micromass $(\mathrm{M}+)$ and static scaffold $(\mathrm{S}+)$ samples in comparison to the non-CM-stimulated $\mathrm{M}$ - and $\mathrm{S}$ - counterparts. No such upregulation was observed in samples maintained in more chondrogenic conditions including Pel, S-, the bioreactor with perfusion, and combined perfusion and OHP. The increase caused by CM supplementation in static scaffold samples was not seen when bACh-agarose constructs were exposed to either perfusion or OHP. Wong et al. (2003) also observed downregulation of Col I when bACh-alginate constructs were subjected to $5 \mathrm{MPa} \mathrm{OHP}$ at $0.5 \mathrm{~Hz}, 3 \mathrm{~h}$ per day for 3 days. Col I expression is also shown to have an inverse relationship with Col II expression and AC phenotype in vitro (Karlsson et al. 2007). Given these scenarios along with our results on $\mathrm{Col} X$ and $\beta 1$ integrin expression, we conclude that shear stress and/or OHP have chondroprotective effects that slow down fibrogenesis.

We also consider that when the data are viewed collectively, the biochemical analysis shows a significant increase in $\mathrm{Col} / D N A$ and GAG/DNA for the more chondrogenic conditions, 
while the Col I analysis in general shows no significant increase when adding perfusion and OHP. The increase in total $\mathrm{Col} / D N A$ is possibly attributable to the generation of other collagen types such as types II, III, VI, IX, XI, XII and XIV (Eyre 2002) and these indices ought to be added in future analyses. We note shear stress and OHP induce expression of GAG a n d Col ECM m a c r o m o l e c u le s, i. e., chondroregenerative effects but also suppress $m R N A$ expression of $\beta 1$ integrin and collagen types I and $\mathrm{X}$, i.e., chondroprotective effects.

\section{Mechanical evaluation}

In this section, a scaffold with cells embedded in it will be thought of as a composite material. In this composite, the agarose scaffold material is more rigid than cells. As such, the higher the cell content in the composite, the softer the composite. However, as cells divide, differentiate and grow an ECM, the stiffness of the biological components, cells and tissue, increase. This is supported by literature studies showing that the addition of bovine nasal septum-derived chondrocytes into PEG-based scaffolds decreased the compressive modulus of the composite scaffold by 1.27 -fold when analyzed $24 \mathrm{~h}$ after seeding (Appelman et al. 2009).

This description of cell-scaffold composite elasticity as cells are added to the scaffold is supported by our results from the 21-day study in Fig. 6. Cell-free agarose scaffolds have an average elastic modulus of $35.0 \pm 1.1 \mathrm{kPa}$, which is near the lower range of that reported in the literature of 50-2000 kPa depending on the molecular weight of the agarose used (Normand et al. 2000). In comparison, elasticities of chondrocytes are 1.1-4 kPa (Darling et al. 2008; Freeman et al. 1994) and the weighted average elasticity of the agarose and cells will show a decrease after incorporation of cells consistent with the 1.55 -fold drop at day 0 observed in our experiments on addition of 250,000 cells on average to a single construct.

As expected, all treatment groups with the exception of the $\mathrm{SP}+$ sample have lower elastic moduli compared to that of the scaffold composites at day 0 . This is because the micromass and pellets do not have the more rigid agarose scaffold and the scaffold constructs have cells that continue to proliferate and produce a soft biological ECM within the agarose. When samples are compared against each other, significant enhancements in elastic moduli occur with 1.6- and 4.7-fold increases with scaffold encapsulation, 2.6- and 19.8-fold increases when adding perfusion and 2.7- and 3.4-fold increases with simultaneous addition of OHP and perfusion when compared to respective $\mathrm{M}-$ and $\mathrm{M}+$ controls. Because mechanical stimulation increases the mechanical properties of the cell- ECM, the cell-ECM-scaffold mechanical properties also increase. These increases are more impressive when considering that M- and M+ samples had 2.31- and 2.05-fold higher elastic moduli compared to Peland Pel+, respectively, which are more representative of growth in vivo, conditions we expect to emulate with agarose matrix. Our current results agree with our prior findings that indicate that perfusion and OHP improve the mechanical properties of the resulting AC tissues, though in past studies there was a synergistic effect in adding TGF- $\beta 3$ to the mechanical stimulus (Nazempour et al. 2016).

Progressive improvements in the elastic moduli by 1.6- and 4.2-fold occur when adding perfusion, $\mathrm{SP}-$ and $\mathrm{SP}+$, to scaffolds alone, $\mathrm{S}-$ and $\mathrm{S}+$. There is no further improvement 
when adding OHP to SP- and a 5.8-fold decline when adding OHP to SP+, but with no decline from what was present with scaffolds alone, S+. We would like to point out that viewing $m R N A$, biochemical and mechanical results collectively has advantages in that one can better see that the elastic modulus increases or is nearly equivalent to $\mathrm{S}-$ and $\mathrm{S}+$, the GAG and Col expression increases with OHP and non-chondrogenic $m R N A$ markers are lower.

One might argue the results contradict previous studies showing improvement in mechanical properties with mechanical stimulation with Mauck et al. (2000) reporting a 6-fold increase in a chondrocyte-seeded agarose disk equilibrium aggregate modulus after 28 days when subjected to dynamic compressive stress. Or Kelly et al. (2006) who observed a higher Young's modulus in dynamically loaded constructs. Yet our results are consistent with those of Lima et al. (2007) who described a negative effect of combined TGF- $\beta 3$ and dynamic unconfined loading on bACh-agarose constructs. Differences in outcomes can relate to how mechanical properties are measured and will depend on the composition of the material tested and the size of those components. AFM-measured properties can vary by as much as 3.8-fold when measured with conical verses spherical probes (Park et al. 2010). Also, tip geometry can affect the distribution of Young's moduli because the tissue is heterogeneous and different tips measure elastic moduli of different components (Stolz et al. 2004). Then, there are different types of physical forces applied, i.e., confined compression (Mauck et al. 2000), unconfined compression (Kelly et al. 2006) and OHP in our studies. Also, differing results may be attributable to donor variation, e.g., age or phenotype of the Chs cultured, as these factors are known to cause significant variations in the resulting ECM (Barbero et al. 2004; DeGroot et al. 1999). Hence, it is important to assure that comparisons are made using the same physical forces and measurement techniques.

Finally, there is evidence in Fig. 6 to indicate that CM supplementation has varied effects on the elastic modulus as a function of culture techniques applied to the same cells used. The elastic modulus decreased by 2.08 -fold and 1.85 -fold with the addition of CM in micromass and pellet cultures, respectively. The decrease in the elastic modulus is in agreement with our previous work with hADSCs in which 3.71- and 4.37-fold decreases were observed in elastic moduli with the addition of $\mathrm{CM}$ for micromass and pellet cultures, respectively (Nazempour et al. 2016). Supplementation with CM also resulted in a 1.65-fold decrease in elastic modulus of SOHP samples. However, this is in contrast to our previous scaffold-free work with hADSCs (Nazempour et al. 2016) where we found that OHP+ samples had significantly higher elastic moduli by 1.9 -fold over OHP- samples. This disparity could perhaps be attributable to the differences in cell types used in these two studies, which ought to be verified in future work. While Lee and Im (2010) and Hwang et al. (2011) showed beneficial effects of TGF- $\beta$ supplementation on ADSC chondrogenesis, Giovannini et al. (2010a, b) showed determintal effects on ECM secretion with TGF- $\beta$ on AChs. In contrast, the elastic moduli of the bACh-scaffolds increased with the addition of CM by 1.40 -fold from $\mathrm{S}-$ to $\mathrm{S}+$ and by 3.69 -fold from $\mathrm{SP}-$ to $\mathrm{SP}+$. This is similar to results reported by Huang et al. (2008), who found a significant time-dependent tensile modulus increase with the addition of CM containing TGF- $\beta 3$ at days 28,42 and 56 by more than 2 -fold. We hypothesize that the elastic modulus in CM-treated samples may be higher simply because there is less ECM in CM-treated samples, as evidenced by the lower $\mathrm{Col} / D N A$ count and 
therefore more agarose. An assessment of $m R N A$ for other cartilage types will be helpful in testing the hypothesis to determine what other structures are contributing to the ECM properties.

\section{Future directions}

Future studies are required to confirm if there is synergy between OHP and perfusioninduced shear stress. We did not study the individual effects of OHP and perfusion because this would require cell-seeded scaffold transfer from Petri dishes to the bioreactors where mechanical stimuli is applied and then back to the Petri dishes when there is no OHP or perfusion of medium. Moving back and forth increases the risk of contamination; however, this can be rectified in future bioreactor designs by use of alternative feed ports that allow replacement of medium without induction of significant shear forces. Other studies are needed to find a combination of mechanical stimuli to best induce chondrogenesis and determine the optimal magnitude of these stimuli. In vitro, dynamic loads have been applied at magnitudes ranging from 0.1 to $10 \mathrm{MPa}$ (Hansen et al. 2001; Hu and Athanasiou 2006; Luo and Seedhom 2007; Meyer et al. 2011; Ogawa et al. 2009) and frequencies ranging from 0.01 to $1 \mathrm{~Hz}$ (Hansen et al. 2001; Hu and Athanasiou 2006; Huang et al. 2004; Meyer et al. 2011; Ogawa et al. 2009) to stimulate cartilage matrix protein expression and improve the compressive properties of the engineered tissues (Bian et al. 2010). Given this, we recommend future factorial design studies to optimize mechanical force magnitudes and their combinations for enhancing chondrogenesis.

There is also a lack of comprehensive studies comparing the effects of different mechanical stimuli such as confined compression, unconfined compression, shear stress, hydrostatic pressure and osmotic pressure as well as dose-response studies. In our system, OHPs of up to $10 \mathrm{MPa}$ and shear stresses of $0.08 \mathrm{~Pa}$ are easily achievable. Even higher shear stresses can be applied by operating the reactor in centrifugal mode, which allows cell suspensions as they are forming constructs to be retained in the system while liquid drag forces are increased. Operation in this mode would require cessation of rotation for the 4-h OHP cycles; however, intermittent application of physical forces is consistent with the literature (Hu and Athanasiou 2006). Given that these studies are costly in terms of culture medium and additives over the 3-week culture times required, adequate resources are needed. Costs in the current study with micromass and pellet controls, scaffolds, perfusion and OHP, all with and without chondrogenic medium, are substantial. Therefore, for future studies on dose-response effects, progress will likely be limited to one factor at a time.

Studies may also focus on the best time to start applying mechanical forces, the duration of such forces, and whether forces should be applied at different magnitudes throughout the culture period. In our study, we pumped medium to the bioreactors right after bACh-agarose constructs were formed and transferred to the bioreactors. We applied OHP $24 \mathrm{~h}$ afterward. While some argue applying mechanical forces could be more effective when applied early in the culture (Angele et al. 2003; Waldman et al. 2006), others argue this may have detrimental effects. We applied OHP $4 \mathrm{~h}$ a day because the time required for proteoglycan synthesis is estimated to be 1.5-2 h (Mitchell and Hardingham 1981). However, it is possible that a longer loading period may be required for other macromolecules to be synthesized. 
Moreover, it may be questioned whether applying mechanical stimuli over a full 3-week period is necessary or if the same results may be obtained by applying mechanical forces at multiple points during the culture period. For example, when cyclic forces are applied for 30 $\mathrm{min}$, a $48 \%$ increase in Col accumulation is found over unstimulated controls over $24 \mathrm{~h}$ (Waldman et al. 2006). Tran et al. (2011) applied $0.5 \mathrm{~N}$ for the first week and increased the force to 10 and $20 \mathrm{~N}$ for the second and third weeks. Hence, time-dependent studies are necessary to provide better understanding and improved protocols for physical stimulation.

Also, the effects of OHP, perfusion and their combination on mass transfer of nutrients is not well studied. Nutrient and oxygen transport limitations caused by consumption by peripheral cells result in heterogeneous constructs with matrix-deficient centers (Curcio et al. 2014). However, to the best of our knowledge, no systematic and quantitative analyses have been carried out to compare metabolic kinetics under static conditions, perfusion or OHP. Future studies are recommended to distinguish the population of live and dead cells throughout the culture period under different conditions using live-dead staining, such as with the use of the yellow tetrazole MTT, which is reduced to purple-colored formazan by living cells (Mosmann 1983).

Though establishing chondrogenic biochemical properties is desirable, the real aim of ACTE is to develop functional tissues with appropriate mechanical properties. As assessed by AFM, none of our tissues developed elastic moduli in the 300-1000 kPa native AC range (Ateshian and Hung 2003, Mansour 2003). It is hypothesized that the elastic modulus could be further improved with the use of other growth factors, longer culture duration and an effective physical stimulation protocol. This is supported by the work of Nims et al. (2014), where, in comparison to a constant supply of TGF- $\beta 3$ and for an untreated control, a transient initial 14th day application of TGF- $\beta 3$ was found to yield a significantly higher Young's modulus by day 45 in bACh-agarose constructs. In addition, the mechanical properties of the scaffold will affect its stability under experimental conditions (Murphy et al. 2012). The bottom line is that the measurement of mechanical properties such as the elastic moduli measured by AFM in our study is paramount and care should be taken when comparing results with literature as differing mechanical properties and measurement techniques are known to affect results.

Mechanotransduction is attributed to interactions between ECM and the cytoskeleton through integrins, deformation of the plasma membrane and the nucleus, ion channels such as voltage-gated sodium and calcium channels, transient receptor potential channels and chloride channels and the primary cilium (Mobasheri et al. 2002; O'Conor et al. 2013). However, the exact sequence of biomechanical and biochemical events that occurs following individual or combined mechanical stimuli represents an area of growing investigation. Future studies are recommended in which protein profiling and whole genome sequencing is carried out to clarify the underlying molecular mechanisms that are affected to understand the fundamentals of AC repair so that the contributions necessary for healthy chondrogenesis can be optimized. Finally, future studies should involve the use of more clinically relevant cell sources such as adult hAChs, hBMSCs, and a coculture of both. 


\section{Conclusions}

The effects of different culturing techniques including micromass, pellet, encapsulation in agarose, exposure to shear stress and exposure to combined shear stress and OHP in the presence and absence of $\mathrm{CM}$ on bACh chondrogenesis were compared. Samples cultured in micromass and pellets do not vary significantly with respect to biochemical and biomechanical properties. However, encapsulation in agarose significantly enhances GAG and Col secretion. To test the effects of shear stress and combined shear stress and OHP on chondrogenesis, we employed our unique perfusion/pressurized bioreactor. The results show the capability of our newly developed bioreactor system for inducing ECM secretion by bAChs encapsulated in agarose hydrogels. Although the precise mechanisms remain unknown, our results indicate that using scaffolds and adding shear stress, followed by OHP lead to stepwise increases in secretion of macromolecules such as GAG and Col, suppressed expression of non-chondrogenic markers such as $\mathrm{Col} \mathrm{X}$ and $\mathrm{Col} \mathrm{I}$ and a reduction in $\beta 1$ integrin and enhancements in elastic properties. Lastly, our results reveal no positive effect of CM supplementation on chondrogenesis.

\section{Acknowledgments}

This project was accomplished with support from an NSF EAGER grant CBET-1212573, an NSF GRDS supplement CBET-1245188, the WSU NIH Protein Biotechnology Training Program grant NIH T32 GM008336-26, a NASA Space Grant, a WSU DRADS fellowship, a Harold P. Curtis Scholarship for Chrystal Quisenberry, as well as salary support for Prof. Van Wie from the USDA NIFA Hatch Project \#WNP00807. The authors also acknowledge Potlatch Pack for the supply of bovine carpal joints, undergraduate students Ashley Davie and Tyler Cheung for their help in isolating bAChs and Gary Held and Miles Pepper from the WSU Voiland College of Engineering and Architecture Machine Shop for assistance in manufacture and assembly of the bioreactor system.

\section{References}

Abu-Lail NI, Camesano TA. The effect of solvent polarity on the molecular surface properties and adhesion of Escherichia coli. Coll Surf B. 2006; 51:62-70.

Angele P, Yoo JU, Smith C, Mansour J, Jepsen KJ, Nerlich M, Johnstone B. Cyclic hydrostatic pressure enhances the chondrogenic phenotype of human mesenchymal progenitor cells differentiated in vitro. J Orthop Res. 2003; 21:451-457. [PubMed: 12706017]

Angele P, Schumann D, Angele M, Kinner B, Englert C, Hente R, Fuchtmeier B, Nerlich M, Neumann C, Kujat R. Cyclic, mechanical compression enhances chondrogenesis of mesenchymal progenitor cells in tissue engineering scaffolds. Biorheology. 2004; 41:335-346. [PubMed: 15299266]

Appelman TP, Mizrahi J, Elisseeff JH, Seliktar D. The differential effect of scaffold composition and architecture on chondrocyte response to mechanical stimulation. Biomaterials. 2009; 30:518-525. [PubMed: 19000634]

Ateshian, G., Hung, C. Functional properties of native articular cartilage. In: Guilak, F.Butler, D.Goldstein, S., Mooney, D., editors. Functional tissue engineering. Springer; New York: 2003. p. 46-68.

Augst A, Marolt D, Freed LE, Vepari C, Meinel L, Farley M, Fajardo R, Patel N, Gray M, Kaplan DL, Vunjak-Novakovic G. Effects of chondrogenic and osteogenic regulatory factors on composite constructs grown using human mesenchymal stem cells, silk scaffolds and bioreactors. J R Soc Interface. 2008; 5:929-939. [PubMed: 18230586]

Badger AM, Cook MN, Lark MW, Newman-Tarr TM, Swift BA, Nelson AH, Barone FC, Kumar S. SB 203580 inhibits p38 mitogen-activated protein kinase, nitric oxide production, and inducible nitric oxide synthase in bovine cartilage-derived chondrocytes. J Immunol. 1998; 161:467-473. [PubMed: 9647257] 
Barbero A, Grogan S, Schafer D, Heberer M, Mainil-Varlet P, Martin I. Age related changes in human articular chondrocyte yield, proliferation and post-expansion chondrogenic capacity. Osteoarthritis Cartilage. 2004; 12:476-484. [PubMed: 15135144]

Barquins M, Maugis D. Adhesive contact of axisymmetric punches on an elastic half-space-the modified Hertz-Hubers stress tensor for contacting spheres. J Mec Theor Appl. 1982; 1:331-357.

Benya PD, Shaffer JD. Dedifferentiated chondrocytes reexpress the differentiated collagen phenotype when cultured in agarose gels. Cell. 1982; 30:215-224. [PubMed: 7127471]

Bian L, Fong JV, Lima EG, Stoker AM, Ateshian GA, Cook JL, Hung CT. Dynamic mechanical loading enhances functional properties of tissue-engineered cartilage using mature canine chondrocytes. Tissue Eng Part A. 2010; 16:1781-1790. [PubMed: 20028219]

Bigdeli N, Karlsson C, Strehl R, Concaro S, Hyllner J, Lindahl A. Coculture of human embryonic stem cells and human articular chondrocytes results in significantly altered phenotype and improved chondrogenic differentiation. Stem Cells. 2009; 27:1812-1821. [PubMed: 19544424]

Bilgen B, Chu D, Stefani R, Aaron RK. Design of a biaxial mechanical loading bioreactor for tissue engineering. J Vis Exp. 2013; 25:50387.

Buschmann MD, Gluzband YA, Grodzinsky AJ, Kimura JH, Hunziker EB. Chondrocytes in agarose culture synthesize a mechanically functional extracellular matrix. J Orthop Res. 1992; 10:745-758. [PubMed: 1403287]

Campbell JJ, Lee DA, Bader DL. Dynamic compressive strain influences chondrogenic gene expression in human mesenchymal stem cells. Biorheology. 2006; 43:455-470. [PubMed: 16912417]

Chai DH, Arner EC, Griggs DW, Grodzinsky AJ. av and $\beta 1$ integrins regulate dynamic compressioninduced proteoglycan synthesis in 3D gel culture by distinct complementary pathways. Osteoarthritis Cartilage. 2010; 18:249. [PubMed: 19800448]

Chao PH, Grayson W, Vunjak-Novakovic G. Engineering cartilage and bone using human mesenchymal stem cells. J Orthop Sci. 2007; 12(4):398-404. [PubMed: 17657563]

Chiang H, Hsieh CH, Lin YH, Lin S, Tsai-Wu JJ, Jiang CC. Differences between chondrocytes and bone marrow-derived chondrogenic cells. Tissue Eng Part A. 2011; 17:2919-2929. [PubMed: 21895487]

Coles JM, Blum JJ, Jay GD, Darling EM, Guilak F, Zauscher S. In situ friction measurement on murine cartilage by atomic force microscopy. J Biomech. 2008; 41:541-548. [PubMed: 18054362]

Cooke ME, Allon AA, Cheng T, Kuo AC, Kim HT, Vail TP, Marcucio RS, Schneider RA, Lotz JC, Alliston T. Structured three-dimensional co-culture of mesenchymal stem cells with chondrocytes promotes chondrogenic differentiation without hypertrophy. Osteoarthritis Cartilage. 2011; 19:1210-1218. [PubMed: 21816228]

Cui X, Breitenkamp K, Finn MG, Lotz M, D’Lima DD. Direct human cartilage repair using threedimensional bioprinting technology. Tissue Eng Part A. 2012; 18:1304-1312. [PubMed: 22394017]

Curcio E, Piscioneri A, Morelli S, Salerno S, Macchiarini P, De Bartolo L. Kinetics of oxygen uptake by cells potentially used in a tissue engineered trachea. Biomaterials. 2014; 35:6829-6837. [PubMed: 24875760]

Darling EM, Topel M, Zauscher S, Vail TP, Guilak F. Viscoelastic properties of human mesenchymally-derived stem cells and primary osteoblasts, chondrocytes, and adipocytes. J Biomech. 2008; 41:454-464. [PubMed: 17825308]

Davisson T, Sah RL, Ratcliffe A. Perfusion increases cell content and matrix synthesis in chondrocyte three-dimensional cultures. Tissue Eng. 2002; 8:807-816. [PubMed: 12459059]

DeGroot J, Verzijl N, Bank RA, Lafeber FP, Bijlsma JW, TeKoppele JM. Age-related decrease in proteoglycan synthesis of human articular chondrocytes: the role of nonenzymatic glycation. Arthritis Rheum. 1999; 42:1003-1009. [PubMed: 10323457]

Detzel CJ, Van Wie BJ. Use of a centrifugal bireactor for cartilaginous tssue frmation from iolated condrocytes. Biotechnol Prog. 2011; 27:451-459. [PubMed: 21290617]

Elder BD, Athanasiou KA. Synergistic and additive effects of hydrostatic pressure and growth factors on tissue formation. PLoS ONE. 2008; 3:e2341. [PubMed: 18523560]

Eyre D. Collagen of articular cartilage. Arthritis Res. 2002; 4:30-35. [PubMed: 11879535] 
Farndale R, Buttle D, Barrett A. Improved quantitation and discrimination of sulphated glycosaminoglycans by use of dimethylmethylene blue. Biochim Biophys Acta. 1986; 883:173177. [PubMed: 3091074]

Fischer-Cripps AC. The Hertzian contact surface. J Mater Sci. 1999; 34:129-137.

Freeman PM, Natarajan RN, Kimura JH, Andriacchi TP. Chondrocyte cells respond mechanically to compressive loads. J Orthop Res. 1994; 12:311-320. [PubMed: 8207584]

Fukuda K, Dan H, Takayama M, Kumano F, Saitoh M, Tanaka S. Hyaluronic acid increases proteoglycan synthesis in bovine articular cartilage in the presence of interleukin-1. J Pharmacol Exper Thera. 1996; 277:1672-1675.

Gemmiti CV, Guldberg RE. Fluid flow increases type II collagen deposition and tensile mechanical properties in bioreactor-grown tissue-engineered cartilage. Tissue Eng. 2006; 12:469-479. [PubMed: 16579680]

Gharravi AM, Orazizadeh M, Hashemitabar M. Fluid-induced low shear stress improves cartilage like tissue fabrication by encapsulating chondrocytes. Cell Tissue Bank. 2016; 17:117-122. [PubMed: 26254592]

Giovannini S, Diaz-Romero J, Aigner T, Heini P, Mainil-Varlet P, Nesic D. Micromass co-culture of human articular chondrocytes and human bone marrow mesenchymal stem cells to investigate stable neocartilage tissue formation in vitro. Eur Cells Mater. 2010a; 20:245-259.

Giovannini S, Diaz-Romero J, Aigner T, Mainil-Varlet P, Nesic D. Population doublings and percentage of S100-positive cells as predictors of in vitro chondrogenicity of expanded human articular chondrocytes. J Cell Physiol. 2010b; 222:411-420. [PubMed: 19890919]

Grashoff C, Aszodi A, Sakai T, Hunziker EB, Fassler R. Integrin-linked kinase regulates chondrocyte shape and proliferation. EMBO Rep. 2003; 4:432-438. [PubMed: 12671688]

Grogan SP, Sovani S, Pauli C, Chen J, Hartmann A, Colwell CW Jr, Lotz MK, D’Lima DD. Effects of perfusion and dynamic loading on human neocartilage formation in alginate hydrogels. Tissue Eng Part A. 2012; 18:1784-1792. [PubMed: 22536910]

Hall AC, Urban JP, Gehl KA. The effects of hydrostatic pressure on matrix synthesis in articular cartilage. J Orthop Res. 1991; 9:1-10. [PubMed: 1984038]

Hansen U, Schunke M, Domm C, Ioannidis N, Hassenpflug J, Gehrke T, Kurz B. Combination of reduced oxygen tension and intermittent hydrostatic pressure: a useful tool in articular cartilage tissue engineering. J Biomech. 2001; 34:941-949. [PubMed: 11410177]

Hasty RT, Garbalosa RC, Barbato VA, Valdes PJ Jr, Powers DW, Hernandez E, John JS, Suciu G, Qureshi F, Popa-Radu M, San Jose S, Drexler N, Patankar R, Paz JR, King CW, Gerber HN, Valladares MG, Somji AA. Wikipedia vs peer-reviewed medical literature for information about the 10 most costly medical conditions. J Am Osteopath Assoc. 2014; 114:368-373. [PubMed: 24778001]

Hering TM, Kollar J, Huynh TD, Varelas JB, Sandell LJ. Modulation of extracellular matrix gene expression in bovine high-density chondrocyte cultures by ascorbic acid and enzymatic resuspension. Arch Biochem Biophys. 1994; 314:90-98. [PubMed: 7944410]

$\mathrm{Hu}$ JC, Athanasiou KA. The effects of intermittent hydrostatic pressure on self-assembled articular cartilage constructs. Tissue Eng. 2006; 12:1337-1344. [PubMed: 16771646]

Huang CYC, Hagar KL, Frost LE, Sun YB, Cheung HS. Effects of cyclic compressive loading on chondrogenesis of rabbit bone-marrow derived mesenchymal stem cells. Stem Cells. 2004; 22:313-323. [PubMed: 15153608]

Huang AH, Yeger-McKeever M, Stein A, Mauck RL. Tensile properties of engineered cartilage formed from chondrocyte- and MSC-laden hydrogels. Osteoarthritis Cartilage. 2008; 16:1074-1082. [PubMed: 18353693]

Hwang NS, Im SG, Wu PB, Bichara DA, Zhao X, Randolph MA, Langer R, Anderson DG. Chondrogenic priming adipose-mesenchymal stem cells for cartilage tissue regeneration. Pharm Res. 2011; 28:1395-1405. [PubMed: 21494923]

Karlsson C, Brantsing C, Svensson T, Brisby H, Asp J, Tallheden T, Lindahl A. Differentiation of human mesenchymal stem cells and articular chondrocytes: analysis of chondrogenic potential and expression pattern of differentiation-related transcription factors. J Orthop Res. 2007; 25:152-163. [PubMed: 17072841] 
Kaupp JA, Weber JF, Waldman SD. Mechanical stimulation of chondrocyte-agarose hydrogels. J Vis Exp. 2012; 27:4229.

Kawanishi M, Oura A, Furukawa K, Fukubayashi T, Nakamura K, Tateishi T, Ushida T. Redifferentiation of dedifferentiated bovine articular chondrocytes enhanced by cyclic hydrostatic pressure under a gas-controlled system. Tissue Eng. 2007; 13:957-964. [PubMed: 17348796]

Kelly TA, Ng KW, Wang CC, Ateshian GA, Hung CT. Spatial and temporal development of chondrocyte-seeded agarose constructs in free-swelling and dynamically loaded cultures. $\mathbf{J}$ Biomech. 2006; 39:1489-1497. [PubMed: 15990101]

Kessler MW, Grande DA. Tissue engineering and cartilage. Organogenesis. 2008; 4:28-32. [PubMed: 19279712]

Khan AA, Suits JM, Kandel RA, Waldman SD. The effect of continuous culture on the growth and structure of tissue-engineered cartilage. Biotechnol Prog. 2009; 25:508-515. [PubMed: 19294749]

Knudson W, Loeser RF. CD44 and integrin matrix receptors participate in cartilage homeostasis. Cell Mol Life Sci. 2002; 59:36-44. [PubMed: 11846031]

Kupcsik L, Stoddart MJ, Li Z, Benneker LM, Alini M. Improving chondrogenesis: potential and limitations of SOX9 gene transfer and mechanical stimulation for cartilage tissue engineering. Tissue Eng Part A. 2010; 16:1845-1855. [PubMed: 20067399]

Kuster MS, Wood GA, Stachowiak GW, Gachter A. Joint load considerations in total knee replacement. The Bone \& Joint Journal react-text: 15. 1997; 79(1):109-13.

Lee DA, Bader DL. Compressive strains at physiological frequencies influence the metabolism of chondrocytes seeded in agarose. J Orthop Res. 1997; 15:181-188. [PubMed: 9167619]

Lee JS, Im GI. Influence of chondrocytes on the chondrogenic differentiation of adipose stem cells. Tissue Eng Part A. 2010; 16:3569-3577. [PubMed: 20597811]

Li Z, Kupcsik L, Yao SJ, Alini M, Stoddart MJ. Mechanical load modulates chondrogenesis of human mesenchymal stem cells through the TGF-beta pathway. J Cell Mol Med. 2010; 14:1338-1346. [PubMed: 19432813]

Lima EG, Bian L, Ng KW, Mauck RL, Byers BA, Tuan RS, Ateshian GA, Hung CT. The beneficial effect of delayed compressive loading on tissue-engineered cartilage constructs cultured with TGF-beta3. Osteoarthritis Cartilage. 2007; 15:1025-1033. [PubMed: 17498976]

Lo IKY, Sciore P, Chung M, Liang S, Boorman RB, Thornton GM, Rattner JB, Muldrew K. Local anesthetics induce chondrocyte death in bovine articular cartilage disks in a dose- and durationdependent manner. Arthroscopy. 2009; 25:707-715. [PubMed: 19560633]

Long R, Hall Matthew S, Wu M, Hui C-Y. Effects of gel thickness on mnicroscopic indentation measurements of gel modulus. Biophys J. 2011; 101:643-650. [PubMed: 21806932]

Loparic M, Wirz D, Daniels AU, Raiteri R, VanLandingham MR, Guex G, Martin I, Aebi U, Stolz M. Micro- and nanomechanical analysis of articular cartilage by indentation-type atomic force microscopy: validation with a gel-microfiber composite. Biophys J. 2010; 98:2731-2740. [PubMed: 20513418]

Luo ZJ, Seedhom BB. Light and low-frequency pulsatile hydrostatic pressure enhances extracellular matrix formation by bone marrow mesenchymal cells: an in-vitro study with special reference to cartilage repair. Proc Inst Mech Eng Part H. 2007; 221:499-507.

Luo S, Shi Q, Zha Z, Yao P, Lin H, Liu N, Wu H, Jin H, Cai J. Morphology and mechanics of chondroid cells from human adipose-derived stem cells detected by atomic force microscopy. Mol Cell Biochem. 2012; 365:223-231. [PubMed: 22403013]

Mansour, J. Biomechanics of Cartilage. In: Oatis, CA., editor. Kinesiology: the mechanics and pathomechanics of human movement. Lippincott Williams and Wilkins; Philadelphia: 2003. p. 66-79.

Mauck RL, Soltz MA, Wang CCB, Wong DD, Chao PHG, Valhmu WB, Hung CT, Ateshian GA. Functional tissue engineering of articular cartilage through dynamic loading of chondrocyteseeded agarose gels. J Biomech Eng. 2000; 122:252-260. [PubMed: 10923293]

McGann LE, Stevenson M, Muldrew K, Schachar N. Kinetics of osmotic water movement in chondrocytes isolated from articular cartilage and applications to cryopreservation. J Orthop Res. 1988; 6:109-115. [PubMed: 3334730] 
Meyer EG, Buckley CT, Steward AJ, Kelly DJ. The effect of cyclic hydrostatic pressure on the functional development of cartilaginous tissues engineered using bone marrow derived mesenchymal stem cells. J Mech Behav Biomed Mater. 2011; 4:1257-1265. [PubMed: 21783134]

Mitchell D, Hardingham T. The effects of cycloheximide on the biosynthesis and secretion of proteoglycans by chondrocytes in culture. Biochem J. 1981; 196:521-529. [PubMed: 6797406]

Miyanishi K, Trindade MCD, Lindsey DP, Beaupre GS, Carter DR, Goodman SB, Schurman DJ, Smith RL. Effects of hydrostatic pressure and transforming growth factor-beta 3 on adult human mesenchymal stem cell chondrogenesis in vitro. Tissue Eng. 2006; 12:1419-1428. [PubMed: 16846340]

Mobasheri A, Carter SD, Martin-Vasallo P, Shakibaei M. Integrins and stretch activated ion channels; putative components of functional cell surface mechanoreceptors in articular chondrocytes. Cell Biol Int. 2002; 26:1-18. [PubMed: 11779216]

Morales TI, Roberts AB. Transforming growth factor beta regulates the metabolism of proteoglycans in bovine cartilage organ cultures. J Biol Chem. 1988; 263:12828-12831. [PubMed: 3166454]

Mosmann T. Rapid colorimetric assay for cellular growth and survival: application to proliferation and cytotoxicity assays. J Immunol Methods. 1983; 65:55-63. [PubMed: 6606682]

Murphy CM, Matsiko A, Haugh MG, Gleeson JP, O’Brien FJ. Mesenchymal stem cell fate is regulated by the composition and mechanical properties of collagen-glycosaminoglycan scaffolds. J Mech Behav Biomed Mater. 2012; 11:53-62. [PubMed: 22658154]

Nazempour A, Van Wie BJ. Chondrocytes, mesenchymal stem sells, and their combination in articular cartilage regenerative medicine. Ann Biomed Eng. 2016; 44:1325-1354. [PubMed: 26987846]

Nazempour A, Quisenberry CR, Van Wie BJ, Abu-Lail NI. Nanomechanics of engineered articular cartilage: synergistic influences of transforming growth factor- $\beta 3$ and oscillating pressure. $\mathrm{J}$ Nanosc Nanotechnol. 2016; 16:3136-3145.

Nims RJ, Cigan AD, Albro MB, Hung CT, Ateshian GA. Synthesis rates and binding kinetics of matrix products in engineered cartilage constructs using chondrocyte-seeded agarose gels. $\mathbf{J}$ Biomech. 2014; 47:2165-2172. [PubMed: 24284199]

Normand V, Lootens DL, Amici E, Plucknett KP, Aymard P. New insight into agarose gel mechanical properties. Biomacromolecules. 2000; 1:730-738. [PubMed: 11710204]

O'Conor CJ, Case N, Guilak F. Mechanical regulation of chondrogenesis. Stem Cell Res Ther. 2013; 4:61.

Ogawa R, Mizuno S, Murphy GF, Orgill DP. The effect of hydrostatic pressure on three-dimensional chondroinduction of human adipose-derived stem cells. Tissue Eng Part A. 2009; 15:2937-2945. [PubMed: 19290804]

Olee T, Grogan SP, Lotz MK, Colwell CW Jr, D’Lima DD, Snyder EY. Repair of cartilage defects in arthritic tissue with differentiated human embryonic stem cells. Tissue Eng Part A. 2013; 19:19.

Park S, Duong C-T, Lee J-H, Lee S-S, Son K. Effect of tip geometry of atomic force microscope on mechanical responses of bovine articular cartilage and agarose gel. Int J Precis Eng Manuf. 2010; 11:129-136.

Porter B, Zauel R, Stockman H, Guldberg R, Fyhrie D. 3-D computational modeling of media flow through scaffolds in a perfusion bioreactor. J Biomech. 2005; 38:543-549. [PubMed: 15652553]

Quisenberry CR, Nazempour A, Van Wie BJ, Abu-Lail NI. Evaluation of $\beta 1$-integrin expression on chondrogenically differentiating human adipose-derived stem cells using atomic force microscopy. Biointerphases. 2016; 11:021005. [PubMed: 27106564]

Sandell LJ, Aigner T. Articular cartilage and changes in arthritis. An introduction: cell biology of osteoarthritis. Arthritis Res. 2001; 3:107-113. [PubMed: 11178118]

Santoro R, Olivares AL, Brans G, Wirz D, Longinotti C, Lacroix D, Martin I, Wendt D. Bioreactor based engineering of large-scale human cartilage grafts for joint resurfacing. Biomaterials. 2010; 31:8946-8952. [PubMed: 20800280]

Santos J, Rebêlo L, Araujo A, Barros E, de Sousa J. Thickness-corrected model for nanoindentation of thin films with conical indenters. Soft Matter. 2012; 8:4441-4448.

Schmid TM, Linsenmayer TF. Immunohistochemical localization of short chain cartilage collagen (type X) in avian tissues. J Cell Biol. 1985; 100:598-605. [PubMed: 2578471] 
Schmittgen TD, Livak KJ. Analyzing real-time PCR data by the comparative C(T) method. Nature Protocols. 2008; 3:1101-1108. [PubMed: 18546601]

Seidel JO, Pei M, Gray ML, Langer R, Freed LE, Vunjak-Novakovic G. Long-term culture of tissue engineered cartilage in a perfused chamber with mechanical stimulation. Biorheology. 2004; 41:445-458. [PubMed: 15299276]

Shintani N, Hunziker EB. Differential effects of dexamethasone on the chondrogenesis of mesenchymal stromal cells: influence of microenvironment, tissue origin and growth factor. Eur Cell Mater. 2011; 22:302-319. [PubMed: 22116649]

Sittinger M, Bujia J, Minuth WW, Hammer C, Burmester GR. Engineering of cartilage tissue using bioresorbable polymer carriers in perfusion culture. Biomaterials. 1994; 15:451-456. [PubMed: 8080936]

Smith RL, Donlon BS, Gupta MK, Mohtai M, Das P, Carter DR, Cooke J, Gibbons G, Hutchinson N, Schurman DJ. Effects of fluid-induced shear on articular chondrocyte morphology and metabolism in vitro. J Orthop Res. 1995; 13:824-831. [PubMed: 8544017]

Stolz M, Raiteri R, Daniels AU, VanLandingham MR, Baschong W, Aebi U. Dynamic elastic modulus of porcine articular cartilage determined at two different levels of tissue organization by indentation-type atomic force microscopy. Biophys J. 2004; 86:3269-3283. [PubMed: 15111440]

Tallheden T, Karlsson C, Brunner A, Van Der Lee J, Hagg R, Tommasini R, Lindahl A. Gene expression during redifferentiation of human articular chondrocytes. Osteoarthritis Cartilage. 2004; 12:525-535. [PubMed: 15219567]

Tekari A, Luginbuehl R, Hofstetter W, Egli RJ. Transforming growth factor beta signaling is essential for the autonomous formation of cartilage-like tissue by expanded chondrocytes. PLoS ONE. 2015; 10:e0120857. [PubMed: 25775021]

Tran SC, Cooley AJ, Elder SH. Effect of a mechanical stimulation bioreactor on tissue engineered, scaffold-free cartilage. Biotechnol Bioeng. 2011; 108:1421-1429. [PubMed: 21274847]

Wagner DR, Lindsey DP, Li KW, Tummala P, Chandran SE, Smith RL, Longaker MT, Carter DR, Beaupre GS. Hydrostatic pressure enhances chondrogenic differentiation of human bone marrow stromal cells in osteochondrogenic medium. Ann Biomed Eng. 2008; 36:813-820. [PubMed: 18266109]

Waldman SD, Couto DC, Grynpas MD, Pilliar RM, Kandel RA. A single application of cyclic loading can accelerate matrix deposition and enhance the properties of tissue-engineered cartilage. Osteoarthritis Cartilage. 2006; 14:323-330. [PubMed: 16324852]

Wang H, Kandel RA. Chondrocytes attach to hyaline or calcified cartilage and bone1. Osteoarthritis Cartilage. 2004; 12:56-64. [PubMed: 14697683]

Wescoe KE, Schugar RC, Chu CR, Deasy BM. The role of the biochemical and biophysical environment in chondrogenic stem cell differentiation assays and cartilage tissue engineering. Cell Biochem Biophys. 2008; 52:85-102. [PubMed: 18841496]

Woessner JF Jr. The determination of hydroxyproline in tissue and protein samples containing small proportions of this imino acid. Arch Biochem Biophys. 1961; 93:440-447. [PubMed: 13786180]

Wong M, Siegrist M, Goodwin K. Cyclic tensile strain and cyclic hydrostatic pressure differentially regulate expression of hypertrophic markers in primary chondrocytes. Bone. 2003; 33:685-693. [PubMed: 14555274]

Xu C, Oyajobi BO, Frazer A, Kozaci LD, Russell RG, Hollander AP. Effects of growth factors and interleukin-1 alpha on proteoglycan and type II collagen turnover in bovine nasal and articular chondrocyte pellet cultures. Endocrinology. 1996; 137:3557-3565. [PubMed: 8754787]

Xu X, Urban JP, Tirlapur U, Wu MH, Cui Z, Cui Z. Influence of perfusion on metabolism and matrix production by bovine articular chondrocytes in hydrogel scaffolds. Biotechnol Bioeng. 2006; 93:1103-1111. [PubMed: 16470872]

Zhang LM, Su PQ, Xu CX, Yang JL, Yu WH, Huang DS. Chondrogenic differentiation of human mesenchymal stem cells: a comparison between micromass and pellet culture systems. Biotechnol Lett. 2010; 32:1339-1346. [PubMed: 20464452]

Zhu Y, Dong Z, Wejinya UC, Jin S, Ye K. Determination of mechanical properties of soft tissue scaffolds by atomic force microscopy nanoindentation. J Biomech. 2011; 44:2356-2361. [PubMed: 21794867] 
a

Micromass (M)

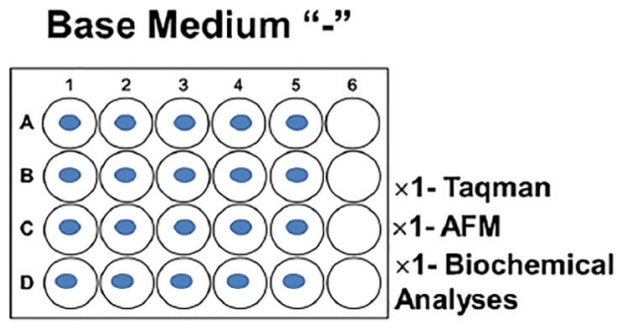

b

Pellet (Pel)

C

Static-scaffold

d

Scaffold-bioreactor Scaffold perfusion Scaffold OHP (SOHP)
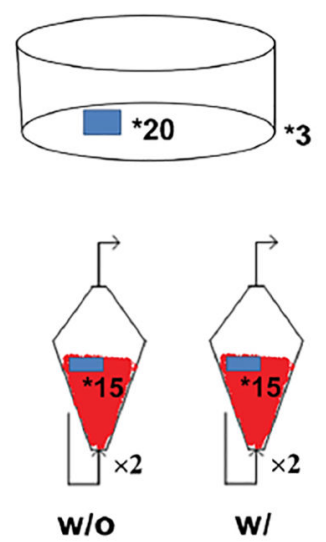

Pressure

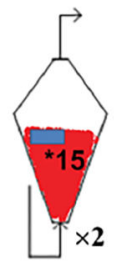

$\times$ 12- Taqman

$\times 4$ - Biochemical

w/

OHP

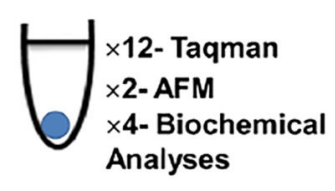

\section{Chondrogenic Medium "+"}

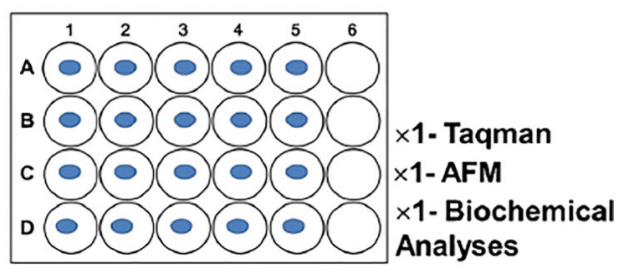

Fig. 1.

Experimental design. a A $10-\mu$ droplet of primary bAChs at a density of $1.6 \times 10^{7}$ viable cells $/ \mathrm{ml}$ was placed in the center of each of 20 wells in three 24 -well culture plates. b $5 \times$ $10^{5} \mathrm{bAChs}$ in $600 \mu \mathrm{l}$ of EM were centrifuged in each of 18 microcentrifuge tube sets at 600 $\mathrm{g}$ for $10 \mathrm{~min}$, c equal volumes of $4 \%$ agarose suspension and a $40 \times 10^{6}$ cells $/ \mathrm{ml}$ suspension were thoroughly mixed. After polymerization, $5 \mathrm{~mm}$ in height bACh-agarose constructs were obtained using a 4-mm biopsy punch. 20 bACh-agarose constructs were maintained in each of three Petri dishes. d 15 bACh-agarose constructs were transferred to each reactor with two replicates at each condition. $*$ and $\times$ give the numbers of constructs or number of replicates 
a
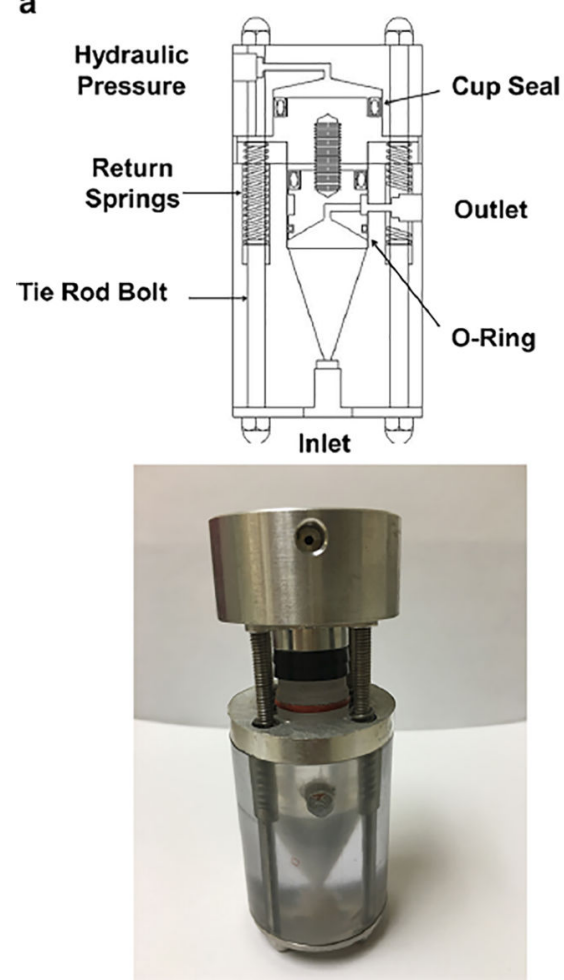

b

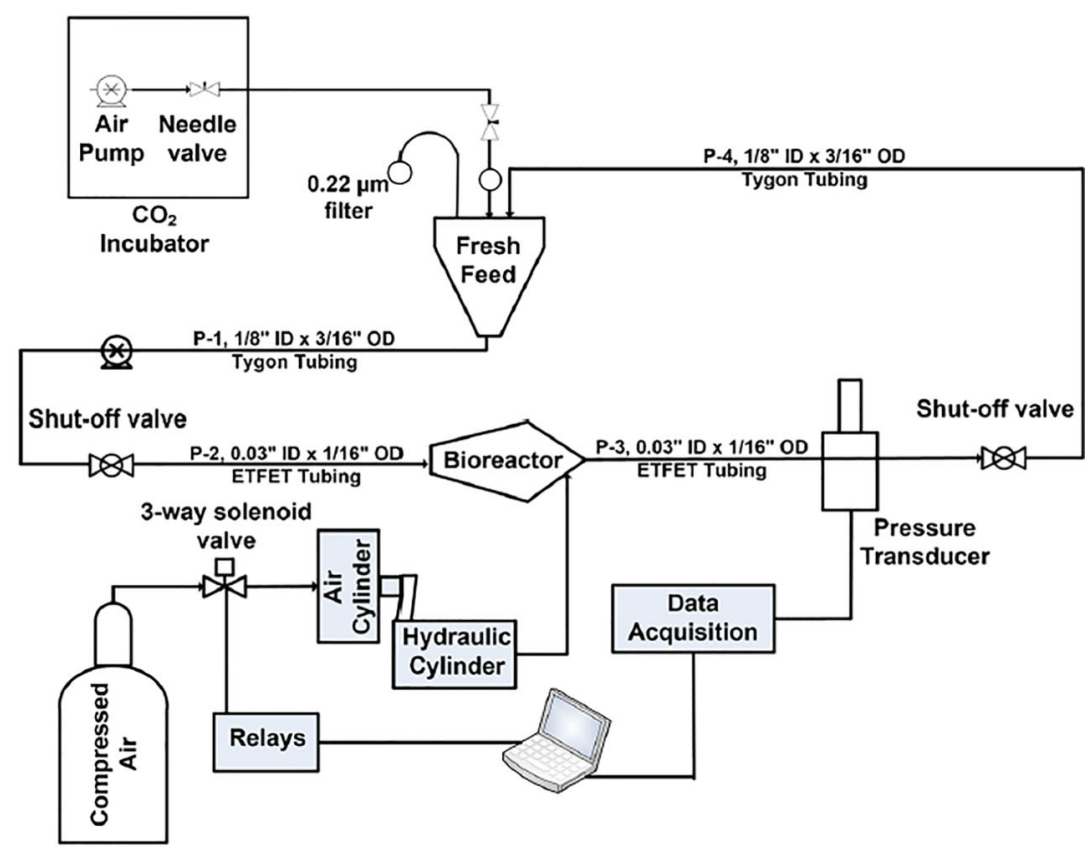

Fig. 2.

a Schematic and photo of the conical-shaped bioreactor made of polycarbonate/stainless steel and topped with double pistons, one made of stainless steel and one made of polycarbonate. b Process flow diagram of perfusion/pressurized computer-controlled bioreactor system 
$\mathbf{a}$

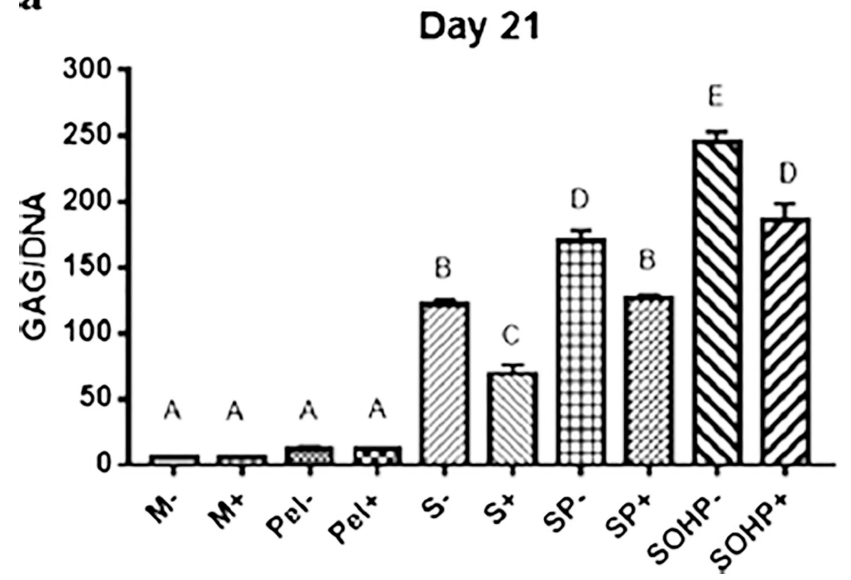

b

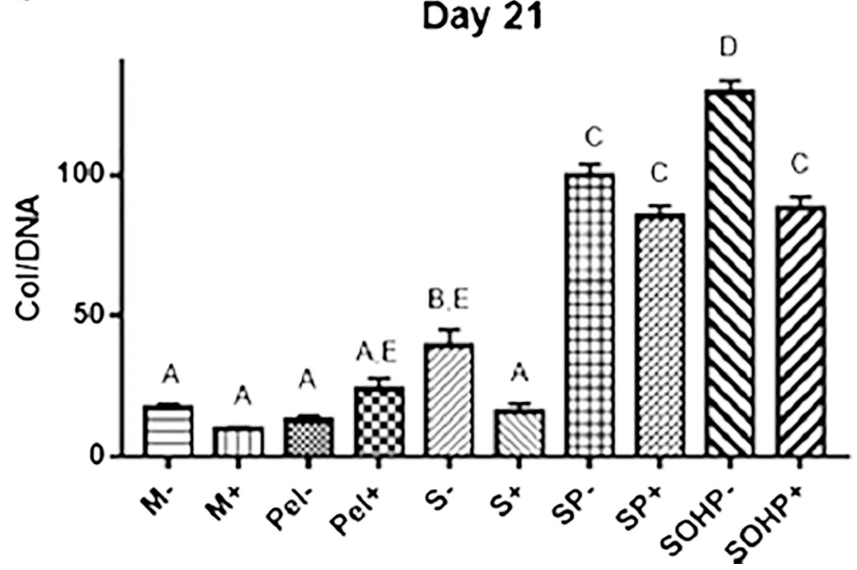

Fig. 3.

Biochemical properties of engineered tissues. a Total GAG content normalized to $D N A$. b Total Col content normalized to DNA. Groups not sharing a letter are significantly different in a one-way ANOVA $(P<0.05)$ with the Tukey post-test. $M$ micromass; Pel pellet, $S$ scaffoldstatic; $S P$ scaffold subjected to perfusion; $S O H P$ scaffold subjected to oscillating hydrostatic pressure; - base medium; + chondrogenic medium 


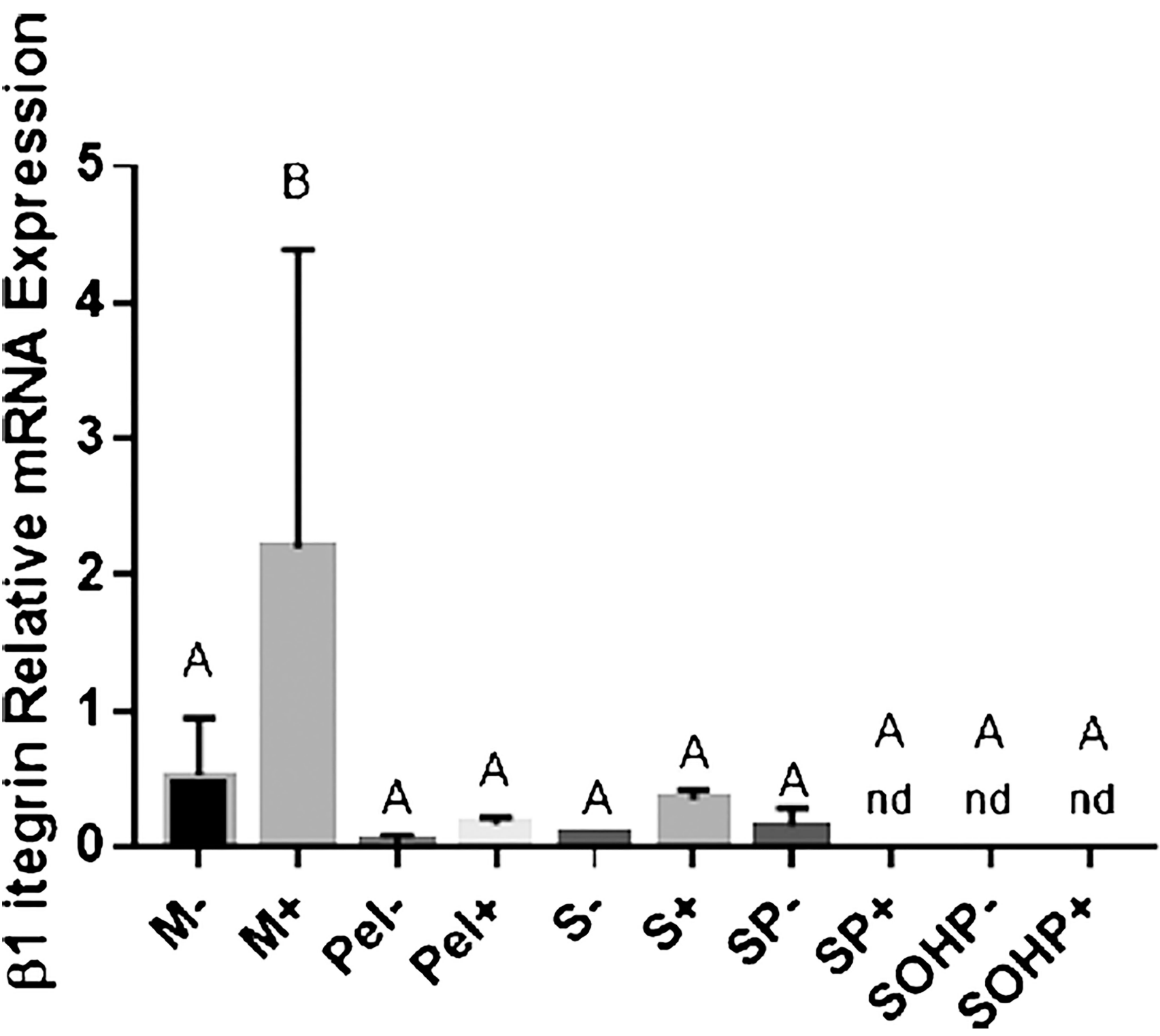

Fig. 4.

$m R N A$ expression of the chondrogenic marker, integrin $\beta 1$ at day 21 . Groups not sharing a letter are significantly different in a one-way ANOVA $(P<0.05)$ with the Tukey post-test. $M$ micromass; Pel pellet, $S$ scaffold-static; $S P$ scaffold subjected to perfusion; $S O H P$ scaffold subjected to oscillating hydrostatic pressure; - base medium; + chondrogenic medium 

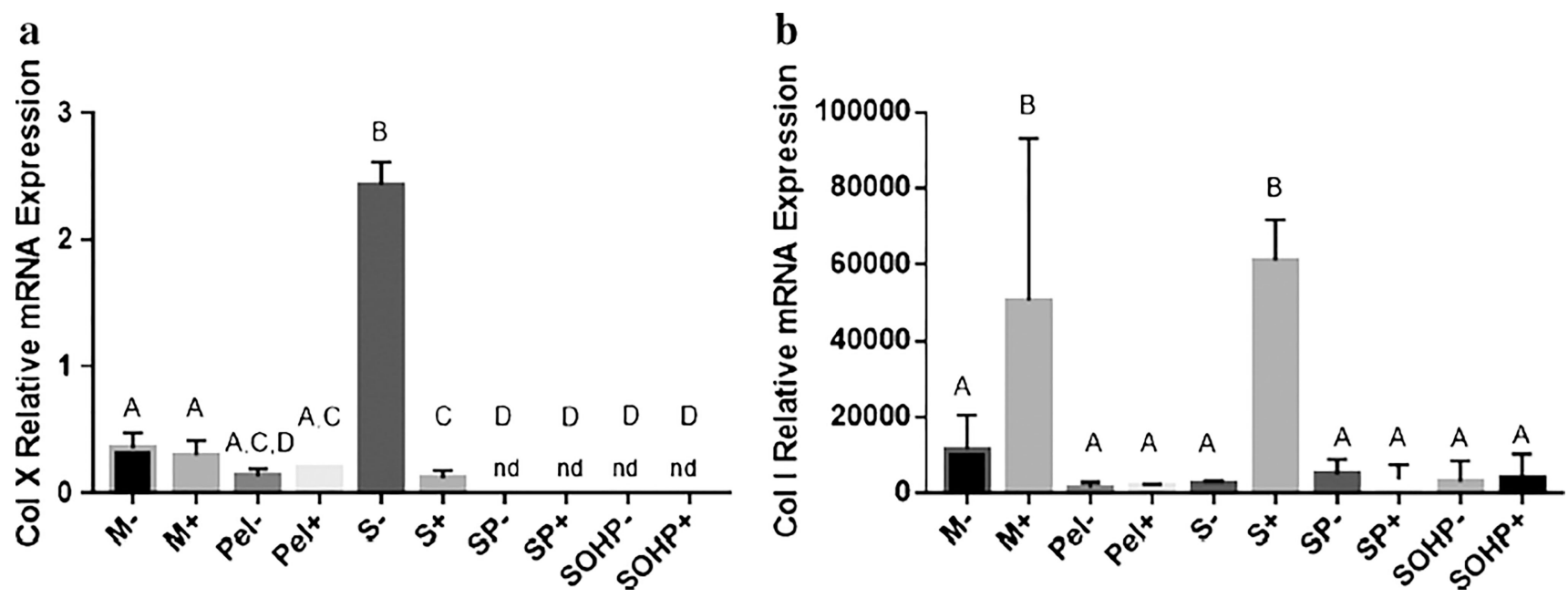

Fig. 5.

$m R N A$ expression of the non-chondrogenic markers. a Col X. b Col I. Groups not sharing a letter are significantly different in a one-way ANOVA $(P<0.05)$ with the Tukey post-test. $M$ micromass; $P$ el pellet, $S$ scaffold-static; $S P$ scaffold subjected to perfusion; $S O H P$ scaffold subjected to oscillating hydrostatic pressure; - base medium; + chondrogenic medium 

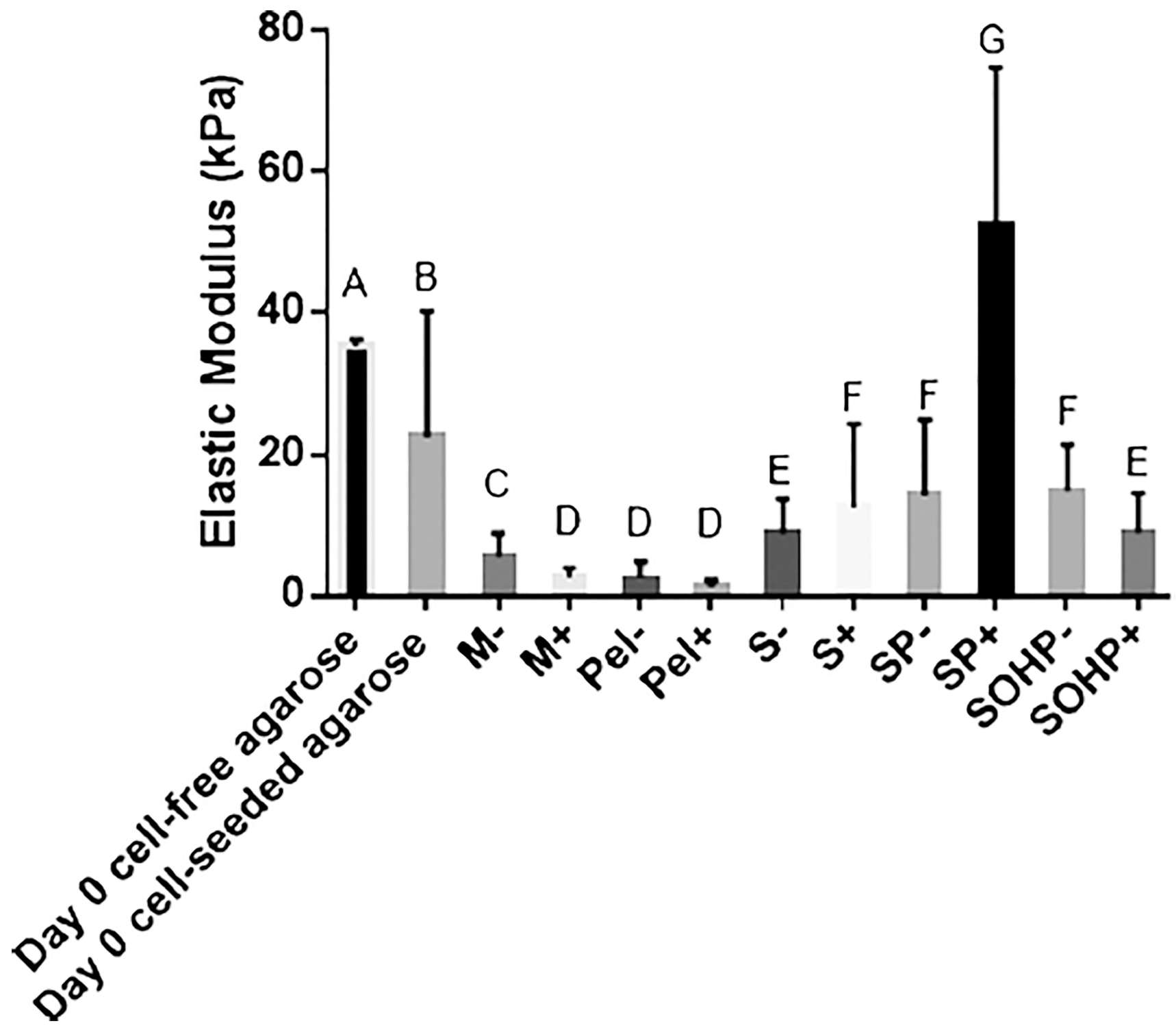

Fig. 6.

Means of distributions of the elastic moduli. Groups not sharing a letter are significantly different by one-way ANOVA $(P<0.05)$ with the Tukey post-test. $M$ micromass; Pel pellet, $S$ scaffold-static; $S P$ scaffold subjected to perfusion; $S O H P$ scaffold subjected to oscillating hydrostatic pressure; - base medium; + chondrogenic medium 


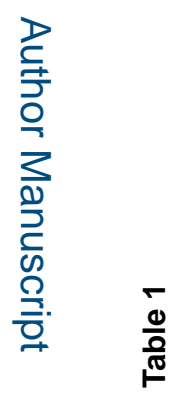

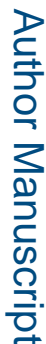

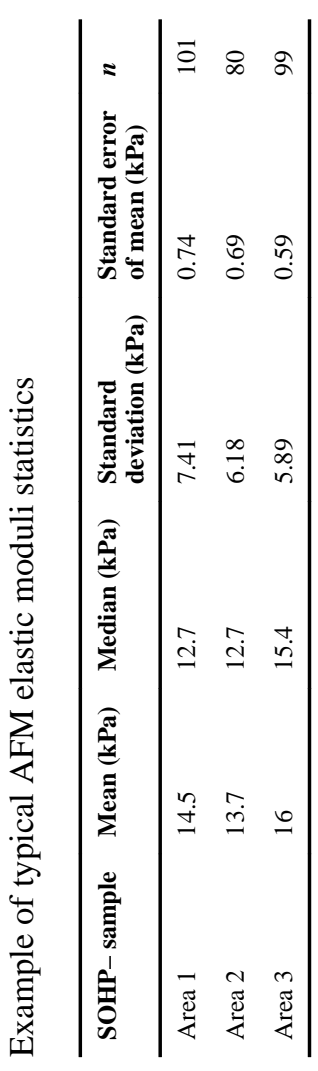

